\title{
Altọapẫ
}

ISSN: 1984-6444 | http://dx.doi.org/10.5902/1984644438228

\section{O direito à educação na perspectiva da justiça distributiva: uma análise sobre a Reforma do Ensino Médio}

The right to education in the perspective of distributive justice: an analysis of the Reform of Secondary Education

\section{Émina Márcia Nery Santos}

Professora Doutora na Universidade Federal do Pará, Belém, Pará, Brasil.

emina@ufpa.br - https://orcid.org/0000-0003-1532-270X

Luziane Said Cometti Lélis

Doutoranda na Universidade Federal do Pará, Belém, Pará, Brasil.

luziane.bim@gmail.com - https://orcid.org/0000-0002-7870-9023

Cassio Vale

Doutorando na Universidade Federal do Pará, Belém, Pará, Brasil.

cassiovale07@yahoo.com.br - https://orcid.org/0000-0002-8956-4536

Recebido em 20 de maio de 2019

Aprovado em 04 de fevereiro de 2020

Publicado em 28 de julho de 2020

\section{RESUMO}

O estudo discute o direito à educação na perspectiva da justiça distributiva preconizada por John Rawls (2017), que articula a igualdade equitativa de oportunidades ao princípio da diferença com a finalidade de possibilitar a ascensão do indivíduo em diversas funções na sociedade. Analisa a concepção de educação e justiça social subjacente à política educacional brasileira que trata do novo Ensino Médio, com foco na Lei oㅜ 13.415/2017, aprovada durante a gestão do ex-presidente Michel Temer (2016-2018), no que diz respeito à sua universalização e finalidade. Por meio da revisão da literatura, evidenciou-se que, embora baseada no princípio da igualdade enquanto direito social, a reforma do Ensino Médio no Brasil revela uma visão utilitarista de formação humana e legaliza a existência de diferentes finalidades educativas para atender aos interesses do capital. Portanto, não se constitui como distributiva e equitativa, mas como reprodutora da desigualdade social presente no projeto de manutenção do status quo.

Palavras-chave: Direito à educação; Ensino médio; Justiça distributiva. 


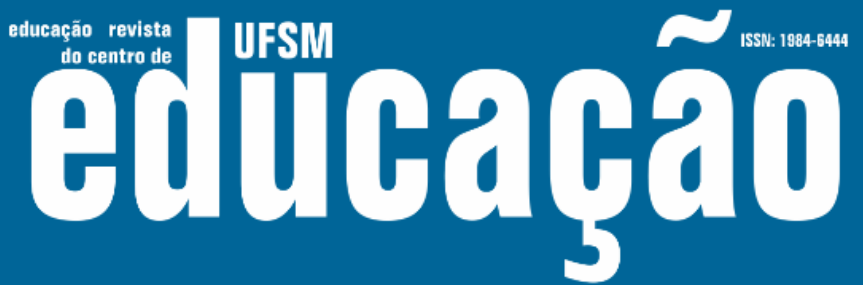

ISSN: 1984-6444 | http://dx.doi.org/10.5902/1984644438228

\section{ABSTRACT}

The study discusses the right to education from the perspective of distributive justice advocated by John Rawls (2017), who articulates the equality of opportunities the principle of difference in order to enable the individual to ascend to various functions in society. It analyzes the conception of education and social justice that underlies the Brazilian educational policy that deals with the new High School, focusing on Law no. 13.415/2017, approved during the management of former president Michel Temer (2016-2018), regarding his universalization and purpose. The review of the literature showed that the reform of secondary education in Brazil, although based on the principle of equality as a social right, reveals a utilitarian vision of human formation and legalizes the existence of different educational purposes to serve the interests of capital, thus not constituting itself as distributive and equitable, but as reproducing social inequality as part of the project of maintaining the status quo.

Keywords: Right to education; High school; Distributive justice.

\section{Nota introdutória}

O estudo discute o direito à educação na perspectiva da justiça distributiva preconizada por John Rawls (2017), que articula a igualdade equitativa de oportunidades ao princípio da diferença, igualando as pessoas em suas circunstâncias - posição social e econômica ou talentos de cada um -, para que possam ascender a diferentes funções na sociedade.

Nesse sentido, o texto tem por objetivo analisar a concepção de educação e justiça social subjacente à política educacional brasileira que trata do Ensino Médio, com foco na Lei no 13.415/2017 (BRASIL, 2017) e ênfase na sua universalização e finalidade. Para isso, estruturamos este artigo em dois tópicos. O primeiro faz um breve apanhado do arcabouço teórico de John Rawls (2017), relativo à proposição de uma teoria da justiça distributiva e equitativa, e do direito à educação enquanto direito humano fundamental para se viver em sociedade com dignidade. O segundo analisa a reforma do Ensino Médio, justamente a Lei n 13.415/2017, fazendo conexão com as políticas educacionais implementadas a partir da década de 1990, focando em seu princípio utilitarista de educação. 


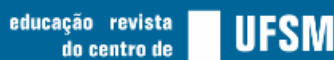 Ellibahao}

ISSN: 1984-6444 | http://dx.doi.org/10.5902/1984644438228

\section{Justiça distributiva e equitativa}

A noção de justiça distributiva remonta ao pensamento aristotélico, sendo decorrente da ideia de mérito e de não obrigatoriedade na distribuição de bens e oportunidades, algo que posteriormente sofre alteração com os pensadores JeanJacques Rousseau, Adam Smith e Immanuel Kant, na compreensão de ajuda aos mais pobres como um dever (BRITO FILHO, 2013). Atualmente, a concepção de justiça distributiva advoga que a distribuição de recursos em uma sociedade deve satisfazer às necessidades de todos os indivíduos, de modo que esta tarefa é atribuída principalmente ao Estado, que gerencia a vida em sociedade e promove políticas sociais públicas, entre elas, a educação, na perspectiva de organização do bem coletivo.

O novo significado de justiça distributiva como equidade é firmado a partir da obra A teoria da justiça de John Rawls, publicada em 1971, que provocou promissores debates em torno da concepção de justiça social e da implementação de políticas públicas contemporâneas, a exemplo de ações afirmativas, justamente em relação ao acesso a bens fundamentais pelos indivíduos numa sociedade, como a educação.

Na medida em que alguns programas criam condições diferenciadas de acesso a determinados recursos importantes para os indivíduos, constituem-se em políticas compensatórias voltadas para a correção de injustiças sociais de parcelas da sociedade em situação de vulnerabilidade. Todavia, mais do que reparar violações praticadas anteriormente, as ações afirmativas servem para proporcionar o acesso dos indivíduos aos bens fundamentais numa sociedade, ultrapassando a igualdade meramente formal, conforme ressalta Brito Filho (2013).

Desta forma, as instituições sociais ganham importância na redução das diferenças sociais porque podem favorecer os indivíduos que socialmente partem em desvantagem. Isso quer dizer que o destino social das pessoas depende do nível de distribuição de bens sociais primários realizado pelas instituições, uma vez que são entendidos como "aqueles bens básicos indispensáveis para satisfazer qualquer plano de vida" (GARGARELLA, 2008, p. 23). 


\section{T uss EutlaghaO}

ISSN: 1984-6444 | http://dx.doi.org/10.5902/1984644438228

Os bens sociais primários correspondem àqueles dependentes das instituições sociais, como as liberdades cívicas, as oportunidades sociais, as riquezas e os direitos totais, em um amplo sistema de liberdade a todos. Os bens naturais primários relacionam-se aos talentos, à saúde e à inteligência dos indivíduos. A distribuição de bens sociais primários depende da maneira como a interação social é articulada, ao contrário do que ocorre com os bens naturais primários, que são adquiridos como numa "loteria". Para tanto, os princípios rawlsianos definem que:

enquanto as liberdades cívicas e as oportunidades devem ser igualmente distribuídas, os [...] poderes e prerrogativas, renda e riqueza admitem uma distribuição desigual, desde que ela esteja sujeita ao critério distributivo maximin: uma distribuição desigual da riqueza e a autoridade é justa apenas no caso em que nenhuma outra forma de articular instituições sociais foi capaz de melhorar as expectativas do grupo menos favorecido. (RAWLS, 2017, p. 34-35, tradução nossa) $)^{1}$.

Assim, os já referidos princípios apresentam uma maneira diferenciada de distribuir os bens sociais primários, desde que nenhuma outra forma de articular instituições sociais seja capaz de melhorar as expectativas do grupo menos favorecido. Portanto, enquanto as liberdades cívicas e as oportunidades devem ser igualmente distribuídas, os poderes e prerrogativas, a renda e riqueza admitem uma distribuição desigual.

O arcabouço teórico de Rawls (2017) alicerça a concepção de justiça liberaligualitária ${ }^{2}$ na defesa da igualdade de liberdades fundamentais, igualdade de oportunidades e de distribuição equitativa de bens econômicos, não necessariamente distribuídos igualmente, a menos que se beneficiem os menos afortunados. Articula a igualdade equitativa de oportunidade com o princípio da diferença - igualdade democrática -, uma vez que os indivíduos não são moralmente responsáveis pelas circunstâncias sociais do nascimento, devendo ter condições efetivas de ascender às diferentes funções e posições (ROSAS, 2011).

De acordo com Brito Filho (2013), o princípio da igualdade equitativa de oportunidades não deve ser conduzido por uma sociedade meritocrática, pois 


\section{N Eutlaghat}

ISSN: 1984-6444 | http://dx.doi.org/10.5902/1984644438228

tem como objetivo garantir que todos tenham acesso, de forma equitativa, aos cargos e posições disponíveis, e isso pode indicar que, em alguns casos, deverá a sociedade dar mais atenção aos que têm menos, em termos de talentos e de condições sociais e econômicas. (BRITO FILHO, 2013, p. 44).

Associado à ideia de igualdade, o princípio da diferença admite a existência de desigualdades, desde que sejam justificadas. Para Gargarella (2008, p. 25), "é o que governa a distribuição dos recursos da sociedade". Desta forma, uma sociedade justa deve respeitar as liberdades fundamentais e proporcionar a igualdade equitativa na distribuição de bens econômicos (nivelando as pessoas na posição social e econômica ou nos talentos de cada um), para que possam elevar-se com dignidade em diferentes funções na sociedade.

Para a efetivação de uma sociedade democrática, Rawls (2017) estabelece regras de prioridade e ordem para se alcançar os princípios de justiça, indicando a liberdade como prioritária em relação à igualdade. Assim, uma sociedade justa deve ser regulada da seguinte forma:

\footnotetext{
Primeiro princípio: Cada pessoa deve ter o direito igual ao mais amplo sistema de liberdades básicas iguais, compatível com um sistema similar de liberdade para todos. Segundo princípio: As desigualdades econômicas e sociais devem ser articuladas de tal forma que, ao mesmo tempo: a) resultem no maior benefício dos menos favorecidos, compatíveis com o princípio da poupança justa, e b) sejam atribuídas a cargos e posições acessíveis a todos em condições de oportunidades iguais. (RAWLS, 2017, p. 34, tradução nossa $)^{3}$.
}

Brito Filho (2013) enfatiza que, ao construir os princípios de justiça, Ralws (2017) elege regras de prioridades, definindo como primeiro princípio o da liberdade liberdades básicas, como liberdade política, de expressão, de reunião, de consciência, de pensamento, além do direito à propriedade privada, etc. O segundo princípio, que se aplica à distribuição de renda e riqueza, é composto de mais dois princípios: a igualdade equitativa de oportunidades e o princípio da diferença.

A teoria de Rawls (2017) surge como alternativa ao utilitarismo, uma doutrina que toma o princípio da utilidade como o único a ser considerado na moral e na legislação, em que tanto predomina o bem sobre o justo quanto os grupos minoritários são aqueles ignorados em detrimento da maior parte dos indivíduos (BRITO FILHO, 


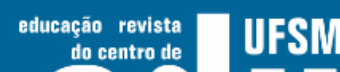 eltioahá}

ISSN: 1984-6444 | http://dx.doi.org/10.5902/1984644438228

2013; ROSAS, 2011). De acordo com Gargarella (2008, p. 11), "o utilitarismo vem a ser perfeitamente compatível com a produção de certas violações de direitos (os direitos de uma minoria) em nome do bem-estar geral - em nome do bem-estar majoritário". Em outras palavras, mesmo que prejudique parte da sociedade, determinada ação pública realizada pelo Estado, a exemplo de uma reforma, será levada adiante porque a maioria da sociedade será beneficiada. Em nome do coletivo, uma parte dele pode sofrer consequências negativas, já que será útil para o bom andamento do convívio social.

Rawls (2017) critica o princípio utilitarista presente em momentos nos quais as organizações sociais tomam como justa a maior soma de satisfação entre os indivíduos, submetendo os direitos individuais ao cálculo do interesse social (THIRYCHERQUES, 2011). Para ele, a fim de equacionar as desigualdades sociais entre os grupos de indivíduos, não basta maximizar a felicidade geral ou dividir igualmente a riqueza, mas distribuí-la desigualmente a fim de beneficiar aos menos favorecidos. Em suma, a justiça distributiva parte do raciocínio distributivo em direção a uma igualdade equitativa de oportunidades, visando a condições vantajosas para todos dentro de uma sociedade.

Desta forma, por não aceitar que as desigualdades possam representar prejuízos aos indivíduos, principalmente aos menos favorecidos, Rawls (2017) elaborou uma teoria da justiça em que utiliza uma estratégia contratualista ${ }^{4}$ particular, em um ambiente imaginário (hipotético) ou contrato hipotético, para servir de base à indicação de princípios $^{5}$ que regem as instituições sociais - como liberdade e igualdade - na distribuição de direitos e deveres entre todos os cidadãos livres, determinando a divisão de vantagens provenientes do sistema de cooperação social, como demonstra a Figura 1 a seguir. 


\section{H Hsm

ISSN: 1984-6444 | http://dx.doi.org/10.5902/1984644438228

Figura 1 - Ponto de partida da teoria rawlsiana

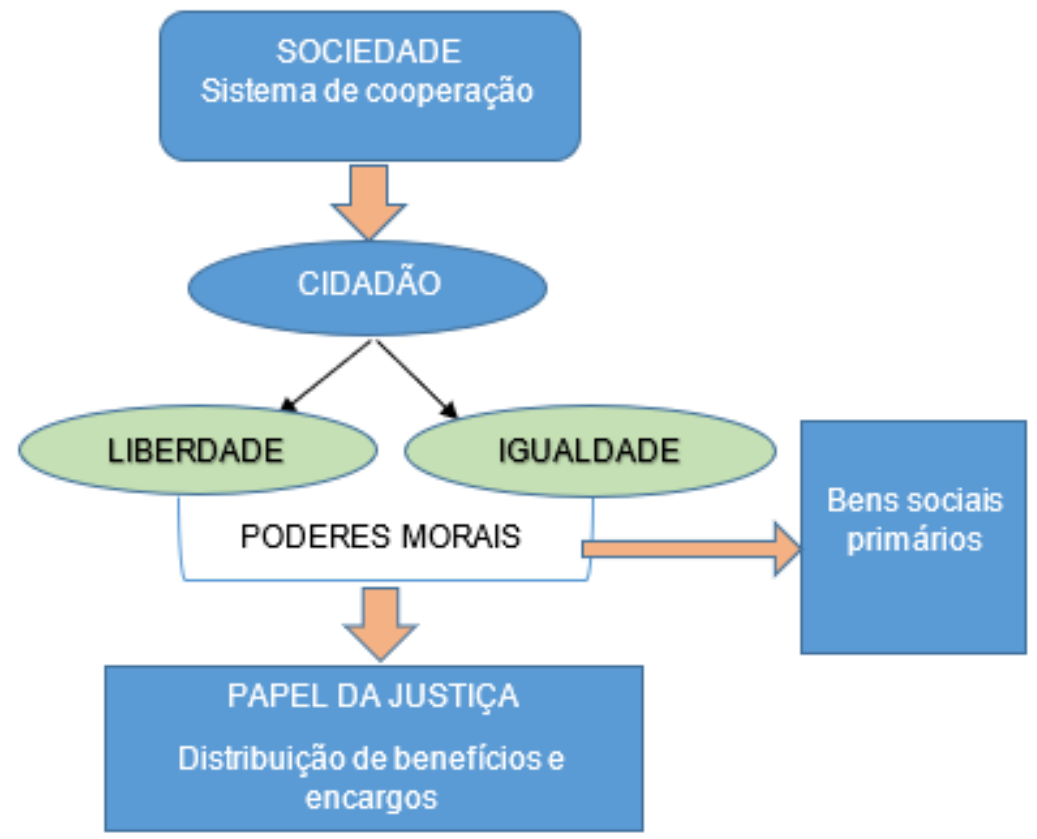

Fonte: elaborado pelos pesquisadores com base em Rosas (2011).

O ponto de partida da teoria rawlsiana encontra-se na definição dos princípios de justiça que irão governar a "estrutura básica da sociedade" 6 - que funciona como regulação e ajuste contínuo das iniquidades, ao mesmo tempo em que se constitui como um sistema de cooperação proporcional às necessidades do cidadão, efetivadas pela distribuição dos bens sociais primários, sociais e naturais, que proporcionam poderes morais. Os bens sociais são dependentes das instituições sociais, a exemplo da riqueza, das oportunidades e dos direitos; já os bens naturais dependem dos indivíduos, seus talentos, sua saúde e inteligência. As instituições sociais precisam respeitar tanto a liberdade, com cada pessoa tendo direito igual a um conjunto de liberdades básicas, quanto a igualdade, devendo-se garantir condições de igualdade de oportunidades e melhorias aos desfavorecidos na distribuição de benefícios e encargos aos cidadãos livres, que é o papel da justiça.

A teoria de Rawls (2017) recebeu críticas de outros autores da corrente liberalista igualitária em relação à distribuição de bens, já que apresentam pontos de contato e de divergência. Apesar disso, essas análises críticas não se constituirão como objeto deste estudo. O que nos interessa é apreender a perspectiva da justiça 


\section{Aitloab̧ão}

ISSN: 1984-6444 | http://dx.doi.org/10.5902/1984644438228

distributiva com equidade, para discutirmos o direito à educação na atualidade em relação às políticas educacionais brasileiras.

Tais teorias estão intimamente associadas ao direito à educação, concebido como um direito social assegurado constitucionalmente pelo Estado, devendo ser ofertado de maneira a beneficiar os menos favorecidos em uma perspectiva de justiça social.

\section{Direito à educação}

O sistema educacional brasileiro sempre esteve vinculado aos interesses econômicos da classe dominante, constituindo-se como território de constante disputa política na sociedade em relação à concretização da ampliação do acesso à escola pública, à institucionalização das formas de financiamento da oferta do serviço e à positivação de normas que definam concepções de qualidade e suas finalidades. Por sua vez, esse processo tem ocasionado a descontinuidade de uma política que efetive esse direito, por conta da oscilação entre avanços e retrocessos sofridos na sua legislação.

A Constituição Federal (CF) de 1988 (BRASIL, 1988) representou um grande avanço em relação às legislações anteriores ao reconhecer a educação como direito social, direito de todos, dever do Estado e da família (BRASIL, 1988, art. 205), além de assegurar a obrigatoriedade e gratuidade do ensino fundamental, inclusive aos que dele não tiveram acesso na idade própria (BRASIL, 1988, art. 208), sendo também configurada como um "direito público subjetivo", conforme explicita o $\S 1^{\circ}$ (BRASIL, 1988, art. 208). Sua promoção tem a finalidade de desenvolver a pessoa para o exercício da cidadania e garantir sua qualificação para o trabalho e a própria sociedade.

Tanto a Constituição Federal quanto o Estatuto da Criança e do Adolescente (ECA), Lei o 8.069/90 (BRASIL, 1990), preveem a atuação de Estado, família e sociedade na garantia os direitos fundamentais, entre eles, a educação, com absoluta prioridade a crianças e adolescentes. Nesse sentido, o art. 53 do Estatuto, estabelece: 


\section{N Usin Eutlathat}

ISSN: 1984-6444 | http://dx.doi.org/10.5902/1984644438228

igualdade de condições para o acesso e permanência na escola; direito de ser respeitado por seus educadores; direito de contestar critérios avaliativos, podendo recorrer às instâncias escolares superiores; direito de organização e participação em entidades estudantis, e acesso à escola pública e gratuita próxima de sua residência. (BRASIL, 1990, art. 53).

Porque a educação é consagrada como direito social, parte integrante dos direitos fundamentais para o alcance da dignidade humana, o Estado possui a obrigação de assegurá-la a todos, incentivando-a em colaboração com a sociedade a fim de torná-la elemento propulsor da cidadania e potencializador da dignidade humana. Por essa razão, é definida por Siqueira Junior e Oliveira (2016, p. 69) como "o atributo moral do indivíduo, que o qualifica enquanto ser", que se exterioriza pelos direitos humanos, portanto, um direito universal.

Especificamente tratando-se do Ensino Médio, objeto de análise deste texto, a intenção legal de garantir o seu acesso a todos ocorreu a partir da Emenda Constitucional no 14/1996 (BRASIL, 1996a), ao substituir o termo "progressiva extensão da obrigatoriedade" por "progressiva universalização" do texto constitucional, ganhando força posteriormente, com a Lei de Diretrizes e Bases (LDB) no 9394/96 (BRASIL, 1996b), pela abrangência dada à educação básica, formada por três etapas: educação infantil, ensino fundamental e ensino médio.

Ademais, a obrigatoriedade do estudo de crianças e adolescentes dos 4 aos 17 anos, como direito positivado, só foi contemplada com a Emenda Constitucional no 59/2009 (BRASIL, 2009a), que acrescentou o § 3ํao art. 76 do Ato das Disposições Constitucionais Transitórias, reduzindo a desvinculação das receitas da União incidentes sobre os recursos destinados à manutenção do ensino e modificando a redação da CF (incisos I e VII do art. 208; § 4 do art. 211; § 3ํ do art. 212 e caput do art. 241), de modo a reconhecer a sua universalização e ampliar os programas suplementares a todas as etapas da educação básica.

Todavia, universalizar pressupõe o acesso, a permanência, a progressão e a conclusão na idade adequada, desenvolvida com qualidade, o que se configura como um grande desafio para o ensino médio. Isso, porque apresenta fatores desfavoráveis, que vão desde a não oferta de matrícula até a queda no percentual da matrícula 


\title{
F Ellibahao
}

ISSN: 1984-6444 | http://dx.doi.org/10.5902/1984644438228

líquida neste nível de ensino, em função dos alunos que concluem o ensino fundamental com atraso em relação à idade.

Estudos sobre a universalização do ensino médio, realizados pelo Instituto Nacional de Estudos e Pesquisas Educacionais Anísio Teixeira (INEP), colocam em cheque a própria universalidade do ensino fundamental, concluindo que o debate sobre essa temática é bastante complexo, pois deveria ocorrer a promoção automática dos alunos no período de 2005 até 2017, como primeiro cenário de possibilidade para universalizar integralmente a última etapa da educação básica (GOULART; SAMPAIO; NESPOLI, 2006).

Corroborando a necessidade de se pensar integralmente múltiplos aspectos em qualquer política direcionada a esse nível de ensino, Moehlecke (2012) argumenta

\begin{abstract}
que a permanência do estudante no ensino médio envolve um conjunto de fatores que podem facilitar ou não esse processo, tais como: idade com que ingressam na escola; inclusão ou não no mercado de trabalho; trajetória escolar anterior; taxas de repetência e evasão; aproveitamento dos estudos; infraestrutura oferecida; qualidade do corpo docente, entre outros. (MOEHLECKE, 2012, p. 44).
\end{abstract}

A idade em que aluno ingressa na escola, a sua trajetória escolar e/ou inclusão no mercado de trabalho, o ensino que não corresponde às suas expectativas, somados às complexas vivências decorrentes de sua condição social, são fatores que influenciam no processo de desenvolvimento da política do ensino médio; não são originários deste nível de ensino, mas acabam desembocando nele. Assim, o desafio pela universalização do ensino médio em um país marcado por diferenças sociais e econômicas, mesmo tendo ampliado o quantitativo de matrícula significativamente em relação ao passado, chega de forma tímida ao final da segunda década do século XXI.

Os jovens e os adultos inseridos no sistema escolar ou não, mesmo tendo direito, ou aqueles que se apresentam em descompasso etário representam uma multiplicidade de identidades, que muitas vezes não reconhece o valor e as vantagens objetivas que os conhecimentos escolares podem trazer para a sua vida. Quanto mais os sujeitos estiverem à margem dos benefícios sociais e econômicos, mais restritivo torna-se esse distanciamento ou desinteresse pela escolarização, 


\section{FTusy Ellloará}

ISSN: 1984-6444 | http://dx.doi.org/10.5902/1984644438228

minimizando perspectivas de querer frequentar o Ensino Superior (BONINI; DRUCK; BARRA, 2018).

De acordo com Bonini, Druck e Barra (2018), a referência para pensar as políticas da última etapa da educação básica precisa levar em conta a trajetória dos jovens na constituição de suas identidades, ou seja, "os sujeitos reais que frequentam ou que têm o direito de frequentá-lo, suas singularidades, suas necessidades, suas expectativas, seus projetos de futuro" (BONINI; DRUCK; BARRA, 2018, p. 34). Esta perspectiva dialoga com o pensamento rawlsiano em torno da justiça distributiva e equitativa, sobretudo, em relação ao direito à educação, pois preconiza a distribuição dos bens sociais - neste caso, a educação - pelas instituições sociais, de maneira a favorecer os indivíduos que socialmente partem em desvantagem. Assim, as políticas voltadas para o ensino médio precisam atender às necessidades dos diferentes sujeitos, com a finalidade de interferir positivamente no destino social daqueles que apresentam desvantagem social e econômica.

Considerando que a educação é uma das mais importantes políticas públicas para a efetivação dos direitos fundamentais - já que altera qualitativamente a forma de inserção social, ao possibilitar aos indivíduos o usufruto dos bens culturais e materiais -, a não garantia dessa política configura-se como violação de direito por parte do Estado. De posse do arcabouço teórico de Rawls (2017) para a garantia do direito à educação, passaremos à análise que objetiva desvelar a concepção de educação e justiça social subjacentes à política educacional brasileira que trata do Ensino Médio, com foco na Lei no 13.415/2017 (BRASIL, 2017). Buscamos conceber se tal reforma foi realizada em benefício dos que mais precisam - os jovens da escola pública brasileira.

\section{A reforma do Ensino Médio como política educacional}

O Ensino Médio brasileiro tem refletido as contradições das relações de poder típicas da nossa sociedade capitalista, resultando na sua descaracterização e na existência de um sistema dual de ensino - propedêutico, para os filhos da classe 


\section{Aitloab̧ão}

ISSN: 1984-6444 | http://dx.doi.org/10.5902/1984644438228

burguesa, e profissional, para os filhos da classe trabalhadora. Para Frigotto, Ciavatta e Ramos (2012),

é neste nível que se revela com mais evidência a contradição fundamental entre capital e o trabalho, expressa no falso dilema de sua identidade: destina-se à formação propedêutica ou à preparação para o trabalho? A história nos permite maior clareza sobre a questão, porque vai revelar a ordenação da sociedade em classes que se distinguem pela apropriação da terra, da riqueza que advém da produção social e da distribuição de saberes. (FRIGOTTO; CIAVATTA; RAMOS, 2012, p. 31).

Ao longo de sua história, o ensino médio passou por sucessivas modalidades e reformas ocasionadas pelas mudanças sofridas pelo Brasil nas várias fases de seu processo produtivo. Foi definido inicialmente pelo modelo de organização tayloristafordista, marcado pela racionalidade técnica e burocrática da linha de montagem, por sua vez substituído pelo toyotismo, com um modo de organização e gestão do trabalho pautado na flexibilidade. Cada sistema de produção demanda características e qualidades distintas para o trabalhador, desencadeando modificações no sistema educacional para a formação do novo trabalhador.

Contudo, como fruto de muitas lutas e pressões da sociedade civil, a partir de instâncias mais articuladas a setores progressistas, a LDB no 9394/96 (BRASIL, 1996b) trouxe alguns avanços para o Ensino Médio, reconhecendo-o como etapa de conclusão da Educação Básica, traduzida sob bases mais humanizadoras e democráticas, com função formativa (BRASIL, 1996b, art. 35), supostamente a fim de superar a dualidade do ensino e promover o encontro sistemático entre "cultura" e "trabalho".

Vale ressaltar que o conceito de educação básica a partir da LDB, aprovada em 1996, apresenta-se sob novas bases, como alicerce e caminho para uma ação política consequente, na avaliação de Cury (2008), pois

como conceito novo, ela traduz uma nova realidade nascida de um possível histórico que se realizou e de uma postura transgressora de situações preexistentes, carregadas de caráter não democrático. Como direito, ela significa um recorte universalista próprio de uma cidadania ampliada e ansiosa por encontros e reencontros com uma democracia civil, social, política e cultural. (CURY, 2008, p. 134). 


\section{ح-1. Eutlaghat}

ISSN: 1984-6444 | http://dx.doi.org/10.5902/1984644438228

Essa legislação previu que o ensino médio pudesse ser ofertado de formas adequadas às necessidades e disponibilidades da população de jovens e adultos, proporcionando condições de acesso e permanência na escola, com a intencionalidade política de constituí-los como seres históricos possuidores de vínculos com a vida produtiva e a cultura. A garantia desse direito significou a ampliação da cidadania dessa população excluída socialmente, do acesso à escola e dos processos de socialização e transmissão de conhecimentos científicos e historicamente produzidos, tão necessários para a sua emancipação.

O currículo integrado no ensino médio em suas diferentes modalidades, visto como um direito do trabalhador brasileiro, é uma necessidade premente e atual, uma conquista e uma construção tardia em relação à qual não se deve aceitar qualquer retrocesso. A oferta do currículo integrado representa a possibilidade de uma formação da totalidade da dimensão humana, compatível com o pensamento rawlsiano sobre o papel que as instituições sociais devem desempenhar no acesso aos bens fundamentais, sobretudo, a educação, assim como na atenuação das diferenças sociais, favorecendo aqueles que partem em desvantagem - conforme o princípio da igualdade equitativa de oportunidade articulado com o princípio da diferença.

Segundo Moehlecke (2012), no ano posterior à promulgação da LDB, uma direção distinta acompanhou o ensino médio, com o decreto no 2.208/97 (BRASIL, 1997) que,

ao definir que a formação profissional de nível técnico no país devia ser organizada de modo independente do ensino médio regular, com uma estrutura curricular própria, dissociando-se, assim, a formação geral da técnica. No entanto, tal decreto foi revogado em 2004, sendo substituído pelo decreto n. 5.154 e, posteriormente, pela lei n. 11.741/08, no âmbito de uma nova política, tanto para o ensino médio quanto para a formação profissional a ele associada, que permitia a realização de ações mais integradas entre ambos. (MOEHLECKE, 2012, p. 41).

A integração curricular do ensino médio com o ensino técnico significa a integração da formação geral à formação técnica, "é uma necessidade conjuntural social e histórica - para que a educação tecnológica se efetive para os filhos dos trabalhadores" (FRIGOTTO; CIAVATTA; RAMOS, 2012, p. 45). Também constitui-se 


\section{Hism etínaráo}

ISSN: 1984-6444 | http://dx.doi.org/10.5902/1984644438228

como condição para se fazer a "travessia" a uma nova realidade. A formação integrada sugere a superação da divisão do ensino em conformidade com a divisão social do trabalho - pensar e executar.

As Diretrizes Curriculares Nacionais para o Ensino Médio (DCNEM), instituídas pela Resolução da Câmara de Educação Básica (CEB) № 3/1998 (BRASIL, 1998), apresentaram novidades, sedução no discurso e hibridez de alguns termos, próprios de um contexto pós-reforma administrativa do Estado brasileiro. Adotam "princípios estéticos, políticos e éticos" (BRASIL, 1998, art. $3^{\circ}$ ) que ressaltam a subjetividade do aluno na constituição de identidades sensíveis e igualitárias, e no testemunho de valores de seu tempo, identificando-os como capazes de suportar a inquietação e conviver com o incerto e o imprevisível. Não obstante, a necessidade de uma aprendizagem ao longo da vida está fundamentada em quatro pilares do conhecimento (aprender a conhecer, aprender a fazer, aprender a conviver juntos, e aprender a ser), proposto no relatório elaborado para a UNESCO sobre a Educação para o século XXI (DELORS, 1998).

Constituem finalidades do ensino médio, de acordo com as DCNEM/98,

desenvolvimento da capacidade de aprender e continuar aprendendo, da autonomia intelectual e do pensamento crítico, de modo a ser capaz de prosseguir os estudos e de adaptar-se com flexibilidade a novas condições de ocupação ou aperfeiçoamento. (BRASIL, 1998, art. 4ํ, inciso I).

Por isso, pauta-se na necessidade de se ter um currículo flexível, interdisciplinar e contextualizado, baseado em competências e habilidades que atendam ao mundo produtivo.

Quanto à possibilidade de um currículo integrado, o texto das DCNEM/98 anuncia que "não haverá dissociação entre a formação geral e a preparação básica para o trabalho, nem esta última se confundirá com a formação profissional" (BRASIL, 1998, art. 12): 


\title{
N Wism EutlathaO
}

ISSN: 1984-6444 | http://dx.doi.org/10.5902/1984644438228

$\S 1^{\circ}$ A preparação básica para o trabalho deverá estar presente tanto na base nacional comum como na parte diversificada.

$\S 2^{\circ} \mathrm{O}$ ensino médio, atendida a formação geral, incluindo a preparação básica para o trabalho, poderá preparar para o exercício de profissões técnicas, por articulação com a educação profissional, mantida a independência entre os cursos. (BRASIL, 1998).

A suposta ruptura sobre a dualidade do ensino médio, oficialmente declarada pelas DCNEM/98, é criticada entre os pesquisadores que desenvolvem estudos sobre trabalho e educação, pois "por um lado, questiona-se a noção de trabalho presente nas diretrizes; por outro, observa-se a contradição entre o discurso presente na lei e as práticas políticas do governo federal para o ensino médio" (MOEHLECKE, 2012, p. 49). Segundo Ramos (2004), a noção de trabalho nas Diretrizes oscila entre práxis humana e trabalho como práxis produtiva, reduzindo a sua concepção a uma função utilitária, na perspectiva do capital e não do trabalhador.

No texto das DCNEM/98, são identificados ainda mecanismos de subordinação da educação ao mercado, referenciado pela lógica gerencial, e de utilização da avaliação como prestação de contas das competências desenvolvidas pela escola. Conforme explicitam os incisos III e V do art. $7^{\circ}$ :

\begin{abstract}
III - instituirão sistemas de avaliação e/ou utilizarão os sistemas de avaliação operados pelo Ministério da Educação e do Desporto, a fim de acompanhar os resultados da diversificação, tendo como referência as competências básicas a serem alcançadas, a legislação do ensino, estas diretrizes e as propostas pedagógicas das escolas;

$\mathrm{V}$ - instituirão mecanismos e procedimentos de avaliação de processos e produtos, de divulgação dos resultados e de prestação de contas, visando desenvolver a cultura da responsabilidade pelos resultados e utilizando os resultados para orientar ações de compensação de desigualdades que possam resultar do exercício da autonomia (BRÁSIL, 1998, art. $7^{\circ}$ ).
\end{abstract}

Contudo, o poder de indução relativamente limitado das Diretrizes não possibilitou uma aproximação entre o que estava presente na lei e o que foi materializado nas práticas políticas do governo federal para o ensino médio. Assim, na tentativa de favorecer uma "inovação" nas escolas de ensino médio não profissional, reorganizando os seus currículos no intuito de "melhorar" a sua qualidade, o Ministério da Educação (MEC) instituiu o Programa do Ensino Médio 


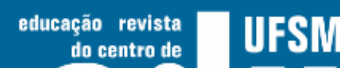 Elínabá}

ISSN: 1984-6444 | http://dx.doi.org/10.5902/1984644438228

Inovador (ProEMI), via portaria no 971/2009 (BRASIL, 2009b). Nas palavras de Moehlecke (2012, p. 45), quer-se estimular a reorganização curricular da escola, de modo a superar a fragmentação do conhecimento, reforçando-se a flexibilização do currículo e desenvolvendo uma articulação interdisciplinar, por áreas de conhecimento, com atividades integradoras definidas com base nos quatro eixos constitutivos do ensino médio - trabalho, ciência, tecnologia e cultura. Desse modo, propõe-se um currículo organizado não apenas em torno de disciplinas, mas também de ações, situações e tempos diversos, assim como de espaços intra e extraescolares para realização de atividades que favoreçam a iniciativa, a autonomia e o protagonismo social dos jovens.

No entanto, na definição de uma nova identidade integrada, percebe-se a utilização de termos, como trabalho, ciência, tecnologia e cultura, que são ressignificados no sentido pragmático para reforçar a flexibilização do currículo e "dotar os indivíduos de comportamentos flexíveis que lhes permitam ajustar-se às condições de uma sociedade" (SAVIANI, 2013, p. 437).

Ademais, questiona-se o fato de o ProEMI "incentivar a articulação, por meio de parcerias, do Sistema $S$ com as redes públicas de ensino médio estaduais" (BRASIL, 2009b, inciso X, parágrafo único, art. $2^{\circ}$ ), contribuindo para o fortalecimento de parcerias público-privadas mediante "celebração de convênio, execução direta ou descentralização de recursos, na forma da legislação aplicável" (BRASIL, 2009b, art. $\left.3^{\circ}\right)$.

Diante das mudanças recentes na legislação e política educacional, com Fundeb e E.C. no 59/2009, das críticas sofridas às DCNEM/98, além das novas exigências educacionais, das alterações no mundo do trabalho e do reconhecimento das necessidades da "juventude", as novas DCNEM são definidas pela Resolução CNE/CEB no 2/2012 (BRASIL, 2012) e pelo Parecer CNE/CEB no 7/2010 (BRASIL, 2010), em articulação com Diretrizes Curriculares Nacionais para a Educação Básica (DCNEB), que na sua conceituação referencial compreendem o direito à educação como parte do princípio de formação da pessoa em sua essência humana (BRASIL, 2013). 


\title{
Aitloab̧ão
}

ISSN: 1984-6444 | http://dx.doi.org/10.5902/1984644438228

As DCNEM/12 concebem o direito à educação como direito social e como qualidade social, construída coletivamente de forma negociada, referendando alguns marcos normativos já vigentes na política adotada para o ensino médio, assim como reforçando a necessidade de um currículo mais atrativo e flexível, com diferentes alternativas, capaz de ampliar a permanência do jovem na escola. Também apresenta uma linguagem mais elucidativa e com referencial teórico menos híbrido. Desta forma, Silva e Colontonio (2014) consideram que,

\begin{abstract}
o texto normativo traz um conjunto de argumentações que buscam qualificar e contextualizar suas proposições: a educação como direito social; o ensino médio com qualidade social; o sentido da escola para as "juventudes"; as especificidades do ensino médio noturno, da educação de jovens e adultos, dos quilombolas, indígenas e do campo, dos estudantes da educação especial estão entre os argumentos que explicam as propostas para a organização curricular segundo essas diretrizes. (SILVA; COLONTONIO, 2014, p. 617).
\end{abstract}

Para atender às finalidades de uma formação humana com base unitária, os fundamentos e pressupostos para um ensino médio considerado de qualidade social devem estar articulados com: trabalho, ciência, tecnologia e cultura; trabalho enquanto princípio educativo; pesquisa como princípio pedagógico; e direitos humanos como princípio norteador (BRASIL, 2013). Vale destacar o acréscimo de princípios outros que precisam estar articulados para uma formação unitária, expressa sob uma perspectiva progressista de educação, sobretudo, nos debates inseridos na temática sobre "trabalho e educação". No entanto, cabe destacar que "as concepções utilizadas nos documentos, analisadas à luz da Teoria Crítica, podem perder seu potencial crítico e emancipador à medida que forem assumidas de maneira instrumental" (SILVA; COLONTONIO, 2014, p. 625).

Moehlecke (2012, p. 55) corrobora a leitura de que as "novas diretrizes" acomodam algumas tensões e divergências, com o desafio não estando mais na superação da dualidade do ensino, mas na "afirmação de uma multiplicidade de significados e trajetórias possíveis de serem construídas ao longo do ensino médio". Essa questão é bastante pertinente, porque evidencia a composição de visões político-ideológicas diferentes em uma mesma legislação na política educacional, 


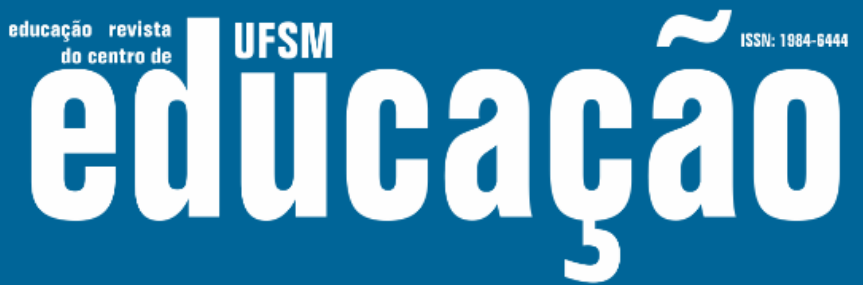

ISSN: 1984-6444 | http://dx.doi.org/10.5902/1984644438228

contrariando a concepção de formação unitária e revelando seu caráter utilitarista no atendimento às demandas do mercado de trabalho. Assim, seguindo a tendência de tornar a organização curricular mais flexível presente nas legislações criadas após a década de 1990, a reforma do Ensino Médio foi imposta pela Medida Provisória no 746/2016 (BRASIL, 2016) e instituída por meio da Lei no 13.415/17 (BRASIL, 2017). Marcadamente pela ausência de diálogo com a sociedade e pela forma autoritária como foi aprovada, ela promove uma série de alterações equivocadas na estrutura deste nível e confirma o retrocesso em relação às conquistas adquiridas nesta última etapa da educação básica.

O objetivo de trazer elementos centrais do marco legal e da política educacional brasileira que trata do Ensino Médio tem por finalidade evidenciar a estreita relação entre ambos, assim como rupturas e confirmações, para em seguida possibilitar uma leitura sobre a concepção de educação e justiça social subjacente à Lei no 13.415/2017 no que diz respeito à universalização e à sua finalidade. A reforma altera em vários artigos o Fundeb, Lei ㄲo 11.494 (BRASIL, 2007), e a LDB, Lei oㅜ9.394/96 (BRASIL, 1996b), a fim de materializar a flexibilização curricular e instituir a política de fomento à implementação de escolas de ensino médio em Tempo Integral (BRASIL, 2017, art. 13) na perspectiva da ampliação do tempo escolar, visando a atingir metas quantitativas, de acordo com o termo de compromisso a ser formalizado entre as partes (BRASIL, 2017, inciso II, parágrafo único), entre outras modificações.

Para tanto, a reforma ignora a luta dos profissionais da educação em torno do fim da dualidade estrutural da última etapa da educação básica e assume um caráter instrumental, em consonância com as orientações internacionais em um contexto de retração do Estado na execução das políticas sociais, sob a égide mercadológica e da ideologia neoliberal. Assim, Mota e Frigotto (2017) consideram a reforma como contrária aos filhos da classe trabalhadora, por ser

imbuída do caráter ideológico instrumental, esta é conduzida como processo natural de modernização - fetichizada pelo determinismo tecnológicoinovador - , despida de relações de poder e sem historicidade. Ou seja, a história de luta voltada para a supressão do dualismo estrutural do Ensino Médio foi rasgada; não há sujeitos históricos, e sim alunos abstratos, jovens trabalhadores deslocados de suas condições objetivas e materiais reais. (MOTA; FRIGOTTO, 2017, p. 357). 


\section{Aitloab̧ão}

ISSN: 1984-6444 | http://dx.doi.org/10.5902/1984644438228

Mota e Frigotto (2017) sintetizam como questões-chave da reforma do ensino médio: o investimento no capital humano visando à maior produtividade; a modernização da estrutura curricular, por meio da flexibilização das áreas de conhecimento; e a melhoria dos resultados do desempenho escolar, articulados no processo formativo de mão de obra barata e sem qualificação de formação humana, já que tem embutida em sua base uma formação fragmentada que pouco contribui para a cidadania plena.

Os direitos e objetivos de aprendizagem estão definidos na Base Comum Nacional Curricular (BNCC) e por itinerários formativos: linguagens e suas tecnologias; matemática e suas tecnologias; ciências da natureza e suas tecnologias; ciências humanas e sociais aplicadas; formação técnica e profissional, organizados por meio da oferta de diferentes arranjos curriculares, considerando a relevância do contexto local e possibilidades dos sistemas de ensino, conforme art. 35-A e 36 da LDB, alterados pela Lei oㅜ 13.415/17 (BRASIL, 2017). Nesse sentido, tanto a BNCC quanto a reforma do Ensino Médio apresentam similitudes quanto a sua função de justiça social, já que pouco colaboram para beneficiar os menos favorecidos que serão impactados por elas.

A esse respeito, a escolha dos itinerários não fica a critério do aluno, como o governo federal divulgou para a sociedade brasileira em propagandas televisivas, mas das condições de oferta do sistema de ensino. Então, se um dos motivos utilizados oficialmente para realizar a restruturação do currículo neste nível de ensino era propiciar o protagonismo juvenil, este se constitui como uma falácia. Ademais, o novo desenho curricular definido pela reforma descaracteriza a concepção de uma educação básica que deveria aprofundar os conhecimentos científicos, já que reduz a carga horária da formação geral e retira a obrigatoriedade de disciplinas consideradas fundamentais para o desenvolvimento de uma formação humana integral. Assim, as únicas disciplinas que serão obrigatórias nos três anos do ensino médio são Português e Matemática, conforme $0 \S 3^{\circ}$ do art. 35 da LDB, alterado pela Lei $n^{\circ}$ 13.415/17 (BRASIL, 2017). Os estudos e práticas de Educação Física, Arte, Sociologia, Filosofia e Língua Inglesa serão apenas incluídos como obrigatórios na BNCC, e o estudo de outras línguas estrangeiras, preferencialmente o espanhol, em 


\section{Eitloabãa}

ISSN: 1984-6444 | http://dx.doi.org/10.5902/1984644438228

caráter optativo, conforme $\circ \S 2^{\circ}$ e $\S 4^{\circ}$ do artigo citado. A importância dada aos conteúdos cobrados em avaliações externas e indicadores de qualidade evidencia o deslocamento do controle dos processos formativos para os resultados, já previstos nas DCNEM/98.

Os outros conhecimentos, tidos como secundários, dar-se-ão mediante a possibilidade de serem cumpridos a distância e por profissionais com notório saber: "para efeito de cumprimento das exigências curriculares do ensino médio, os sistemas de ensino poderão reconhecer competências e firmar convênios com instituições de educação a distância com notório reconhecimento" (BRASIL, 2017, art. 35, §11).

A diversificação dos percursos formativos no ensino médio alinha-se à perspectiva internacional de educação, pois entende que esta cumpra a missão de fazer com que todos frutifiquem os seus talentos e potencialidades criativas, o que implica, por parte de cada um, a capacidade de responsabilizar-se pela realização do seu projeto pessoal (DELORS, 1998).

Essa concepção de educação coloca toda a responsabilidade do sucesso sobre o indivíduo e, na avaliação aqui realizada, é utilitária porque o investimento no capital humano atende a uma maior produtividade requerida pela reestruturação produtiva $e$ também em relação aos filhos da classe trabalhadora que precisam ingressar no mercado de trabalho. Ainda assim, contraria o princípio da justiça distributiva e equitativa defendida por Rawls (2017), pois não oferece nenhuma condição além daquelas que o indivíduo já possui para ascender na sociedade. Assim, a meritocracia passa a ser a base dessa política educacional, que resulta em forjadas condições de acesso a todos. Transfigura-se, portanto, em uma pretensa universalidade.

A multiplicidade de trajetórias formativas no ensino médio não atende à finalidade da última etapa da educação básica, sendo prejudicial para a juventude brasileira que majoritariamente frequenta a escola pública. Isso porque retira o direito de uma formação ampla e reforça as desigualdades sociais existentes, uma vez que a juventude que frequenta a escola privada não será atingida com as mudanças da atual reforma. Para tanto, na concepção de Rawls (2017), o Estado deveria oferecer mais oportunidades a quem tem menos condições, tanto econômicas quanto em relação aos seus talentos. 


\section{Tw HEM GilloaḩO}

ISSN: 1984-6444 | http://dx.doi.org/10.5902/1984644438228

\section{Considerações finais}

O marco legal analisado sobre o ensino médio revela a existência de distintas visões político-ideológicas disputando espaço na materialização da formação das juventudes, inclusive com expressões ressignificadas, o que camufla a verdadeira intenção de manutenção social. Com isso, a proposta de formação integrada no Ensino Médio é, neste momento, adequada às necessidades e disponibilidades da população de jovens e adultos, de forma a possibilitar condições de acesso e permanência na escola. Porém, é preciso superar barreiras, posto que o acesso a essa etapa educacional não é igualitário nem universal, considerando a diversificação nas modalidades ofertadas, que exacerba a desigualdade no atendimento ao que seria um direito igualitário de todos.

A reforma do Ensino Médio expressa as marcas de uma sociedade desigual, que desrespeita um dos direitos fundamentais dos jovens e adultos constituintes de sua demanda - a educação -, embora seja reconhecido em sua Carta Magna como direito social. Isso revela uma visão utilitarista de formação humana, não distributiva e equitativa, porque parte de situações desiguais sem oferecer condições desiguais, aumentando assim a desigualdade que existe no país. Assim, as concepções de educação e justiça social subjacentes à política educacional brasileira que trata do Ensino Médio, em relação a sua universalização e finalidade, não expressam traços de justiça social equitativa para atender aos diretos de todos, em especial, dos que mais precisam. O direito à educação com essa política é, por todo o exposto, ofertado de forma fragmentada em uma perspectiva utilitarista porque sua oferta e implementação foram arquitetadas para garantir o cumprimento de interesses de grupos dominantes na sociedade para manutenção do status quo.

\section{Referências}

BONINI, Adair; DRUCK, Iole de Freitas; BARRA, Eduardo Salles de Oliveira. (Org.) Direitos à aprendizagem e ao desenvolvimento na educação básica: subsídios ao currículo nacional. Curitiba: UFPR, 2018. No prelo. Disponível em: tinyurl.com/sj86t3h. Acesso em: 10 jul. 2018. 


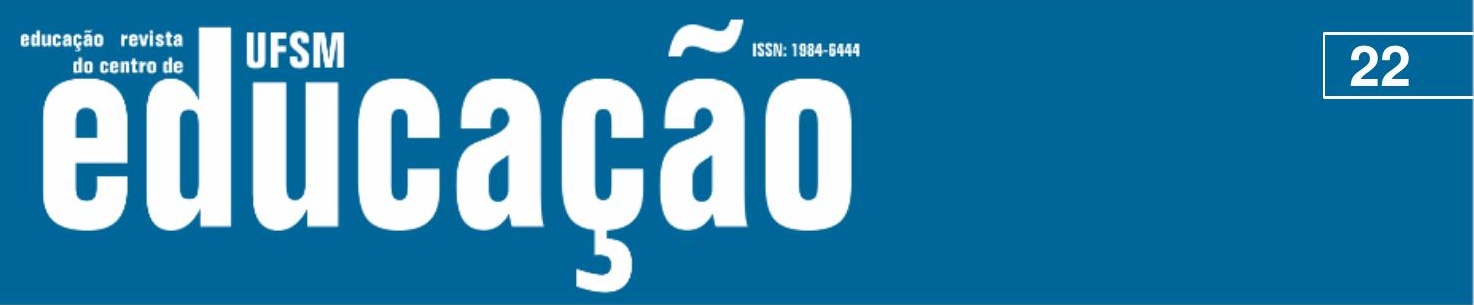

ISSN: 1984-6444 | http://dx.doi.org/10.5902/1984644438228

BRASIL. [Constituição (1988)]. Constituição da República Federativa do Brasil. Brasília, DF: Presidência da República, [1988]. Disponível em: tinyurl.com/sp2ttn6. Acesso em: 10 jul. 2018.

BRASIL. Lei no 8.069, de 13 de julho de 1990. Dispõe sobre o Estatuto da Criança e do Adolescente, e dá outras providências. Brasília, DF: Presidência da República, [1990]. Disponível em: tinyurl.com/qp8f48o. Acesso em: 10 jul. 2018.

BRASIL. Emenda Constitucional no 14, de 12 de setembro de 1996. Modifica os arts. 34, 208, 211 e 212 da Constituição Federal e dá nova redação ao art. 60 do Ato das Disposições Constitucionais Transitórias. Brasília, DF: Câmara dos Deputados e Senado Federal, [1996a]. Disponível em: tinyurl.com/onoz7bu. Acesso em: 10 jul. 2018.

BRASIL. Lei no 9.394, de 20 de dezembro de 1996. Estabelece as diretrizes e bases da educação nacional. Brasília, DF: Presidência da República, [1996b]. Disponível em: tinyurl.com/rwn4j5w. Acesso em: 10 jul. 2018.

BRASIL. Decreto no 2.208, de 17 de abril de 1997. Regulamenta o $§ 2^{\circ}$ do art. 36 e os arts. 39 a 42 da Lei no 9.394, de 20 de dezembro de 1996. Brasília, DF:

Presidência da República, [1997]. Disponível em: tinyurl.com/trugna7. Acesso em: 10 jul. 2018.

BRASIL. Conselho Nacional de Educação. Resolução CEB n 3, de 26 de junho de 1998. Institui as Diretrizes Curriculares Nacionais para o Ensino Médio. Diário Oficial da União, Brasília: Imprensa Nacional, n. 148, p. 21, 5 ago. 1998. Disponível em: tinyurl.com/tdpwzts. Acesso em: 10 jul. 2018.

BRASIL. Lei no 11.494, de 20 de junho de 2007. Brasília, DF: Presidência da República, [2007]. Disponível em: tinyurl.com/yaccf7dq. Acesso em: 10 jul. 2018.

BRASIL. Emenda Constitucional no 59, de 11 de novembro 2009. Brasília, DF: Presidência da República, [2009a]. Disponível em: tinyurl.com/v89ft99. Acesso em: 10 jul. 2018.

BRASIL. Ministério da Educação. Portaria no 971, de 9 de outubro de 2009. Institui o Programa Ensino Médio Inovador. Diário Oficial da União, Brasília: Imprensa Nacional, n. 195, p. 52, 13 out. [2009b]. Disponível em: tinyurl.com/rh7dhq3. Acesso em: 10 jul. 2018.

BRASIL. Ministério da Educação. Parecer CNE/CEB nํ 7, de 7 de abril de 2010. Diretrizes Curriculares Nacionais Gerais para a Educação Básica. Diário Oficial da República, Brasília: Imprensa Nacional: Seção 1, p. 10, 09 jul. [2010]. Disponível em: tinyurl.com/y7u8g3q5. Acesso em: 10 jul. 2018. 


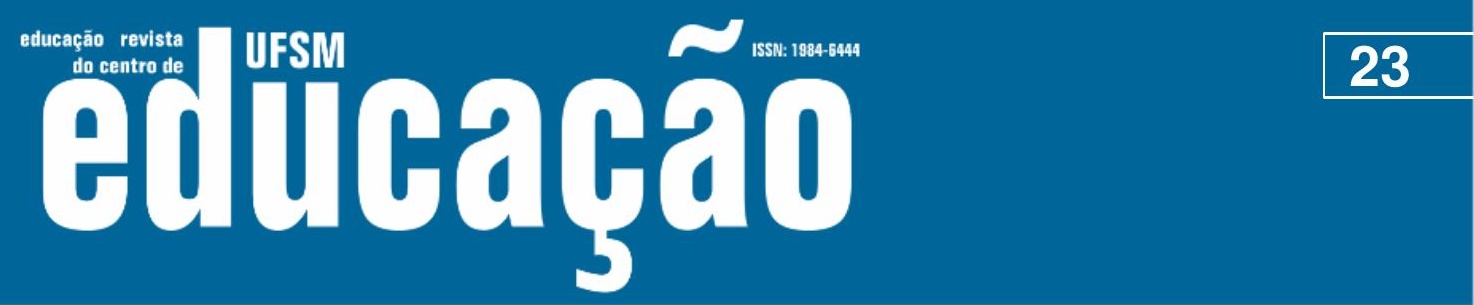

ISSN: 1984-6444 | http://dx.doi.org/10.5902/1984644438228

BRASIL. Conselho Nacional de Educação. Resolução CNE/CEB nº 2, de 31 de janeiro de 2012. Define Diretrizes Curriculares Nacionais para o Ensino Médio. Diário Oficial da União, Brasília: Imprensa Nacional, n. 22, p. 20, 31 jan. [2012]. Disponível em: tinyurl.com/rxzenk8. Acesso em: 10 jul. 2018.

BRASIL. Ministério da Educação. Diretrizes Curriculares Nacionais Gerais da Educação Básica. Brasília: MEC, 2013.

BRASIL. Medida Provisória no 746, de 22 de setembro de 2016. Brasília, DF: Presidência da República, [2016]. Disponível em: tinyurl.com/wsrhfcb. Acesso em: 10 jul. 2018.

BRASIL. Lei no 13.415, de 16 de fevereiro de 2017. Brasília, DF: Presidência da República, [2017]. Disponível em: tinyurl.com/uokvlhv. Acesso em: 10 jul. 2018.

BRITO FILHO, José Claudio Monteiro de. Ações afirmativas. São Paulo: LTr, 2013. CURY, Carlos Roberto Jamil. A Educação Básica como direito. Cadernos de Pesquisa, São Paulo, v. 38, n. 134, p. 293-303, maio/ago. 2008. DOI: dx.doi.org/10.1590/S0100-15742008000200002.

DELORS, Jacques. (Org.). Educação um tesouro a descobrir educação: relatório para a UNESCO da comissão internacional sobre educação para o século XXI. São Paulo: Cortez; Brasília: MEC: UNESCO, 1998.

FRIGOTTO, Gaudêncio; CIAVATTA, Maria; RAMOS, Marise. A gênese do Decreto n. 5.154/2004: um debate no contexto controverso da democracia restrita. Possibilidades e desafios na organização do currículo integrado. In: FRIGOTTO, Gaudêncio; CIAVATTA, Maria; RAMOS, Marise (Org.). Ensino médio integrado: concepções e contradições. São Paulo: Cortez, 2012. p. 21-56.

GARGARELLA, Roberto. As teorias da justiça depois de Rawls: um breve manual de filosofia política. São Paulo: Editora WMF, 2008.

GOULART, Oroslinda Taranto; SAMPAIO, Carlos Eduardo. Moreno; NESPOLI, Vanessa. $O$ desafio da universalização do ensino médio. Brasília: Instituto Nacional de Estudos e Pesquisas Educacionais Anísio Teixeira, 2006.

MOEHLECKE, Sabrina. O ensino médio e as novas diretrizes curriculares nacionais: entre recorrências e novas inquietações. Revista Brasileira de Educação, Rio de Janeiro, v. 17, n. 49, p. 39-58, jan./abr. 2012. DOI: dx.doi.org/10.1590/S141324782012000100003

MOTA, Vânia Cardoso da; FRIGOTTO, Gaudêncio. Por que a urgência da reforma do ensino médio? Medida Provisória no 746/2016 (Lei no 13.415/2017). Educação \& Sociedade, Campinas, v. 38, n. 139, p. 355-372, abr./jun. 2017. DOI: dx.doi.org/10.1590/es0101-73302017176606 


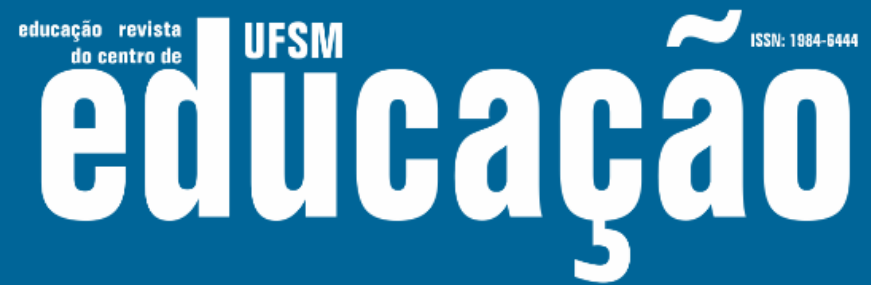

ISSN: 1984-6444 | http://dx.doi.org/10.5902/1984644438228

RAMOS, Marise. O projeto unitário de ensino médio sob os princípios do trabalho, da ciência e da cultura. In: FRIGOTTO, Gaudêncio; CIAVATTA, Maria (Org.). Ensino médio: ciência, cultura e trabalho. Brasília, DF: MEC; SEMTEC, 2004. p. 37-52.

RAWLS, John. Justicia como equidade: materiales para una teoria de la justicia. Madrid: Editorial Tecnos, 2017.

ROSAS, João Cardoso. Concepções da justiça. Lisboa: Edições 70, 2011.

SAVIANI, Dermeval. História das idéias pedagógicas no Brasil. Campinas: Autores Associados, 2013.

SILVEIRA, Denis Coitinho. Justificação pública: a função da ideia de estrutura básica da sociedade em Rawls. Kriterion, Belo Horizonte, v. 52, n. 123, p. 197-211, jun. 2011. DOI: dx.doi.org/10.1590/S0100-512X2011000100011

SILVA, Monica Ribeiro da; COLONTONIO, Eloise Médice. As Diretrizes Curriculares Nacionais para o Ensino Médio e as proposições sobre trabalho, ciência, tecnologia e cultura reflexões necessárias. Revista Brasileira de Educação, Rio de Janeiro, v. 19, n. 58, jul./set. 2014. DOI: dx.doi.org/10.1590/S1413-24782014000800005

SIQUEIRA JUNIOR, Paulo Hamilton; OLIVEIRA, Miguel Augusto Machado de. Direitos Humanos: liberdades públicas e cidadania. 4. ed. São Paulo: Saraiva, 2016.

THIRY-CHERQUES, Hermano Roberto. John Rawls: a economia moral da justiça. Sociedade e Estado, Brasília, v. 26, n. 3, p. 551-563, set./dez. 2011. DOI: dx.doi.org/10.1590/es0101-73302017176606

\section{Notas}

1 "mientras que las libertades cívicas y las oportunidades han de distribuirse por igual [...], los poderes y prerrogativas, la renta y la riqueza admiten una distribución desigual, con tal que se sujete al criterio distributivo maximin: una distribución desigual de la riqueza y la autoridad es justa sólo en el caso de que ninguna outra forma de articular las instituciones sociales fuera capaz de mejorar las expectativas del grupo menos favorecido [...]".

${ }^{2}$ Consiste em uma reconstrução do ideário da teoria política de tradição liberal, dentro de uma interpretação social-democrática, fortemente igualitária (RAWLS, 2017). 


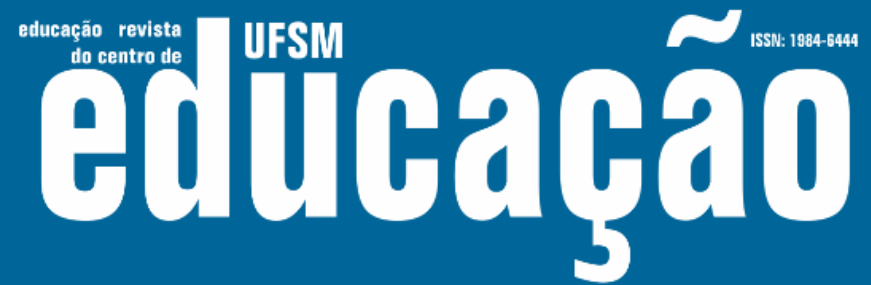

ISSN: 1984-6444 | http://dx.doi.org/10.5902/1984644438228

3 "Primer principio: Cada persona há de tener un igual derecho al más amplio sistema de iguales liberdades básicas compatible com un sistema similar de libertad para todos. Segundo principio: Las desigualdades económicas y sociales han de articularse de modo que al mismo tiempo: a) redunden en el mayor beneficio de los menos favorecidos, compatible com el principio de ahorros justos, y b) estén adscritas a cargos y posiciones accesibles a todos en condiciones de equitativa igualdad de oportunidades".

${ }^{4}$ Nega a desigual capacidade de negociação, forçando o desenvolvimento de uma preocupação com a imparcialidade na promoção do bem de seus membros.

${ }^{5}$ Os princípios de justiça definidos para governar as estruturas básicas da sociedade são construídos numa "posição original", na qual os sujeitos estão sob um "véu de ignorância" que os impede de conhecer as posições religiosas ou morais de si mesmas e dos outros.

1 "Sendo a estrutura básica da sociedade a forma em que as instituições sociais e políticas podem assegurar um sistema de cooperação social, garantindo deveres e direitos e regulando a divisão das vantagens, pode-se dizer que é esta estrutura básica justa o que assegura a justiça de fundo" (SILVEIRA, 2011, p. 204).

\section{Correspondência}

Émina Márcia Nery Santos - Rua Augusto Corrêa, 01, Guamá, Universidade Federal do Pará, CEP: 66075-110, Belém, Pará, Brasil.

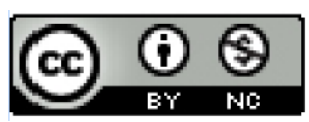

This work is licensed under a Creative Commons Attribution-NonCommercial 4.0 International (CC BY-NC 4.0) 